\title{
Social Determinants of the Health of Urban Populations: Methodologic Considerations
}

\author{
Danielle C. Ompad, Sandro Galea, Waleska T. Caiaffa, and David Vlahov
}

\begin{abstract}
A full understanding of the role of the urban environment in shaping the health of populations requires consideration of different features of the urban environment that may influence population health. The social environment is key to understanding the way in which cities affect the health of populations. Social determinants of health (SDH) are important, generally, yet can have different effects in different settings from urban to rural, between countries, between cities, and within cities. Failure to acknowledge, and more importantly, to understand the role of SDH in health and access to health and social services will hamper any effort to improve the health of the population. In this paper, we will briefly summarize a few key SDH and their measurement. We will also consider methodologic tools and some methodologic challenges. The concepts presented here are broadly applicable to a variety of settings: developed and developing countries, slum areas, inner cities, middle income neighborhoods, and even higher income neighborhoods. However, our focus will be on some of the more vulnerable urban populations who are most profoundly affected by SDH.
\end{abstract}

KEYWORDS Social determinants of health, Urban slums, Health disparities.

A full understanding of the role of the urban environment in shaping the health of populations requires consideration of different features of the urban environment that may influence population health. The study of the social determinants of health (SDH) is embedded in the recognition that the solutions to poor health, material deprivation, lack of access to health care, clean water, sanitation, and the like are not simply alleviated with the provision of resources or technical assistance. ${ }^{1}$ Rather, it is the understanding that when available, access to resources and technical assistance is often socially determined. ${ }^{2}$

The focus of this paper will be SDH in urban settings. In simplest terms, social determinants are, "the social characteristics in which living takes place." 3 The determinants include unemployment, unsafe workplaces, urban slums, globalization and lack of access to health systems. ${ }^{4} \mathrm{SDH}$ also include social factors such as place of residence, race and ethnicity, gender, and socioeconomic status. ${ }^{5}$ In this paper, we will briefly summarize a few key SDH and their measurement. We will also consider methodologic tools and some methodologic challenges. The concepts presented here are broadly applicable to a variety of settings: developed and developing countries,

Ompad, Galea, and Vlahov are with the Center for Urban Epidemiologic Studies, New York Academy of Medicine, New York, USA; Galea is with the Department of Epidemiology, School of Public Health, University of Michigan, Ann Arbor, USA; Caiaffa is with the Departamento de Medicina Preventiva e Social, Faculdade de Medicina, Universidade Federal de Minas Gerais, Belo Horizonte, Brazil.

Correspondence: Danielle C. Ompad, Center for Urban Epidemiologic Studies, New York Academy of Medicine, New York, USA. (E-mail: dompad@nyam.org) 
slum areas, inner cities, middle income neighborhoods, and even higher income neighborhoods. However, our focus will be on some of the more vulnerable urban populations who are most profoundly affected by SDH.

\section{KEY SOCIAL DETERMINANTS OF HEALTH}

Features of the social environment can both harm and promote health in urban settings. Although we summarize some key pathogenic and salutogenic SDH, the examples provided here are illustrative but by no means exhaustive. We refer the reader to other works for a more comprehensive consideration of the urban social environment and SDH. ${ }^{6-9}$

Place of residence and an individual's status within the place are important determinants of health in urban settings. Indeed, as pointed out by Vlahov et al. in this issue, urban is in and of itself an SDH. Industrial activity can have significant impact on cities with respect to pollution, and less expensive housing is often found in areas with less desirable physical environments. Natural and manmade disasters have also affected health in neighborhoods (e.g., environmental pollutants in lower Manhattan after 9/11), cities (e.g., methyl isocyanate gas in Bhopal, India), and regions (e.g., 2004 Indian Ocean tsunami, Hurricane Katrina).

It is important to recognize that the place of residence is situated within a particular social milieu that can have substantial impacts on health in terms of exposure and access to care. Slum dwellers are often a particularly vulnerable group for a variety of reasons including precarious or nonexistent land tenure, ${ }^{10}$ lack of urban resource infrastructure, ${ }^{11}$ and tenuous relationships with governments and law enforcement. ${ }^{10}$ Immigrants living in ethnic enclaves within cities may have different experiences than immigrants living in areas in which they are among the minority, or there is no majority. For example, a study of immigrant mothers in New York City (USA) noted substantial differences in geographical access to prenatal clinics by country of origin. ${ }^{12}$

Race and ethnicity are constructs that classify population groups based upon economic, social, cultural, behavioral and biologic factors; ${ }^{13}$ there are no generally agreed upon definitions, ${ }^{14}$ and the terms are often used interchangeably. ${ }^{15}$ The associations between race/ethnicity and health are complex and often multifactorial. Some population groups are more likely to have specific diseases because of allelic inheritance (e.g., Tay-Sacks disease among Ashkenazi Jews). In other cases, differences in rates of disease among groups are related to differences in likelihood of exposure or access to care.

Racism is discrimination based on race or ethnicity. Racism can affect heath by restricting access to material resources; educational, economic, and occupational opportunities; and health and social services. ${ }^{16}$ It has also been hypothesized that stress resulting from experiencing racism is associated with health outcomes. ${ }^{17,18}$ The association between racism and health has been shown in a variety of settings including New Zealand, ${ }^{19,20}$ the UK, ${ }^{21}$ and the USA. ${ }^{22,23}$

The examination of gender as an SDH is not simply the comparison of disease and exposure for women vs men. Gender moves beyond the biology of being male and female and focuses on the roles and norms of men and women in a given society. ${ }^{24}$ When thinking about gender as an SDH, it is important to distinguish between women's and men's health (restricted to women and men, respectively, and focusing on their particular health needs) and the role of gender as a social construct that shapes personal health behaviors and health-related societal structures. 
When gender is considered in the context of SDH, this generally refers to women's social position in society and reduction of gender inequalities in health outcomes, access to health services, access to educational and employment activities, etc. The need for gender equality and women's empowerment has been a key focus in the global response to HIV/AIDS as underscored by recent language in the United Nations General Assembly Special Session (UNGASS) 2006 resolution, ${ }^{25}$ which pledged to eliminate or reduce gender inequalities, gender-based abuse, violence, and discrimination and increase the capacity of women and adolescent girls to protect themselves from the risk of HIV infection.

Socioeconomic status (SES) refers to an individual's position in society. ${ }^{13}$ Researchers have used a variety of indicators to understand SES including (but not limited to) poverty, income, material deprivation, education, and occupation. ${ }^{26}$ SES is both positively and negatively associated with health; the direction of the association is often disease and setting dependent. For example, in Tshwane (South Africa), higher suicide mortality was associated with high SES, ${ }^{27}$ whereas in Australia and the USA, suicide mortality was associated with lower SES. ${ }^{28,29}$

Income inequality is the relative distribution of income with a city or neighborhood and is sometimes operationalized with the Gini coefficient. ${ }^{30}$ Income inequality is thought to operate through material and psychosocial pathways to shape population health independently of absolute income. For example, Subramanian et al. $^{31}$ reported a significant association between self-rated health and communitylevel income inequality among adults in Chile, even after adjusting for absolute household and community income. A recent study has suggested that disparities in child malnutrition among socioeconomic groups in sub-Saharan Africa are higher in urban than rural settings (Table 1), and intra-urban differences are larger than urban-rural differences, but there is significant variation between countries. ${ }^{32}$

Education provides the skills that enable the acquisition of economic, social, and psychological resources. ${ }^{33}$ As with other measures of SES, education can be

TABLE 1 Urban-rural and intra-urban inequities in the association between child malnutrition and SES 32

\begin{tabular}{lcc}
\hline & Urban to Rural & Intra-Urban \\
\cline { 2 - 3 } \multicolumn{1}{c}{ Country } & Odds ratio & Odds ratio \\
\hline Burkina Faso & 1.9 & 2.3 \\
Cameroon & 1.6 & 2.6 \\
Chad & 1.5 & 1.8 \\
Côte d'Ivoire & 1.5 & 2.4 \\
Ghana & 1.8 & 1.9 \\
Kenya & 1.5 & 3.4 \\
Madagascar & 1.2 & 2.2 \\
Malawi & 2.1 & 2.3 \\
Mozambique & 1.7 & 3.8 \\
Nigeria & 1.6 & 3.1 \\
Tanzania & 3.0 & 3.5 \\
Togo & 1.8 & 2.2 \\
Uganda & 1.6 & 3.0 \\
Zambia & 1.5 & 1.4 \\
Zimbabwe & 1.4 & 2.0 \\
\hline
\end{tabular}


associated with both negative and positive health outcomes. In Scania (Sweden), educational level at the individual and municipality/city level has been shown to be associated with poor psychological health. ${ }^{34}$ However, the association between education and health is not always straightforward. In a multicountry study of plasma lipids and years of schooling, total cholesterol decreased as years of schooling increased for American Whites, while total cholesterol increased as years of schooling increased among American Blacks and the populations sampled in China, Israel, Poland, and Russia. ${ }^{35}$ These differences suggest that social status measures may influence health differently based on the stage of social and economic development of the setting.

Generally, urban education levels are higher than rural education levels. Figures 1 and 2 depict the relationship between measures of urbanicity and urbanization ${ }^{36}$ and female literacy at the country level. ${ }^{37}$ Literacy rates for women are generally higher in countries where the prevalence of urbanicity is high, but in rapidly urbanizing countries, literacy rates for women are low-the same relation is observed among men. Although these relationships imply that education is homogenous across settings, marked disparities in education level have been observed within cities by income. $^{38}$

\section{METHODOLOGIC CONSIDERATIONS IN THE STUDY OF THE URBAN SOCIAL ENVIRONMENT}

\section{Measuring Social Determinants of Health in Urban Settings}

Measuring SDH is important for several reasons. Data on SDH are needed to understand why there are differences in health outcomes between groups. Rarely are

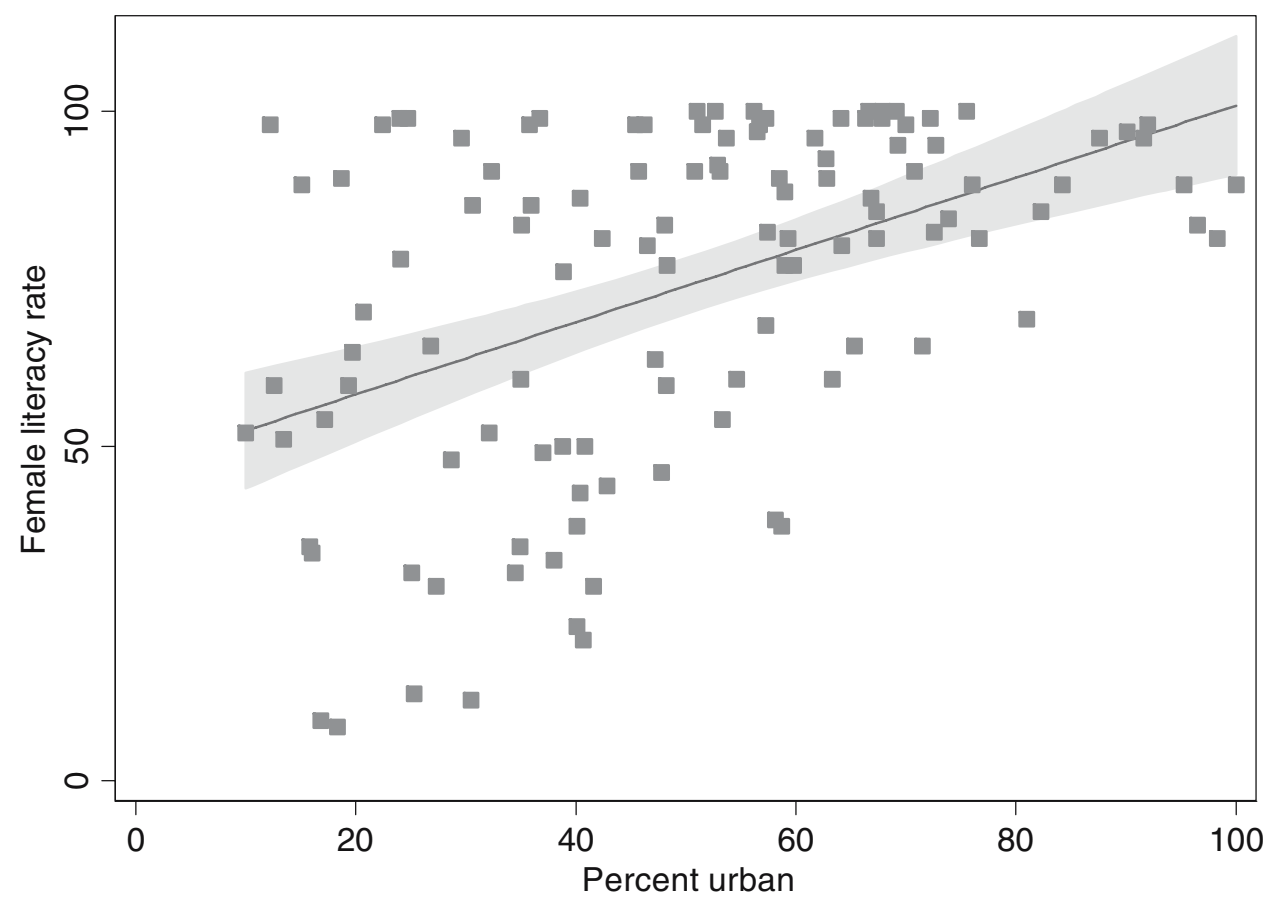

FIGURE 1. Female literacy rate and urbanicity (percent urban). 


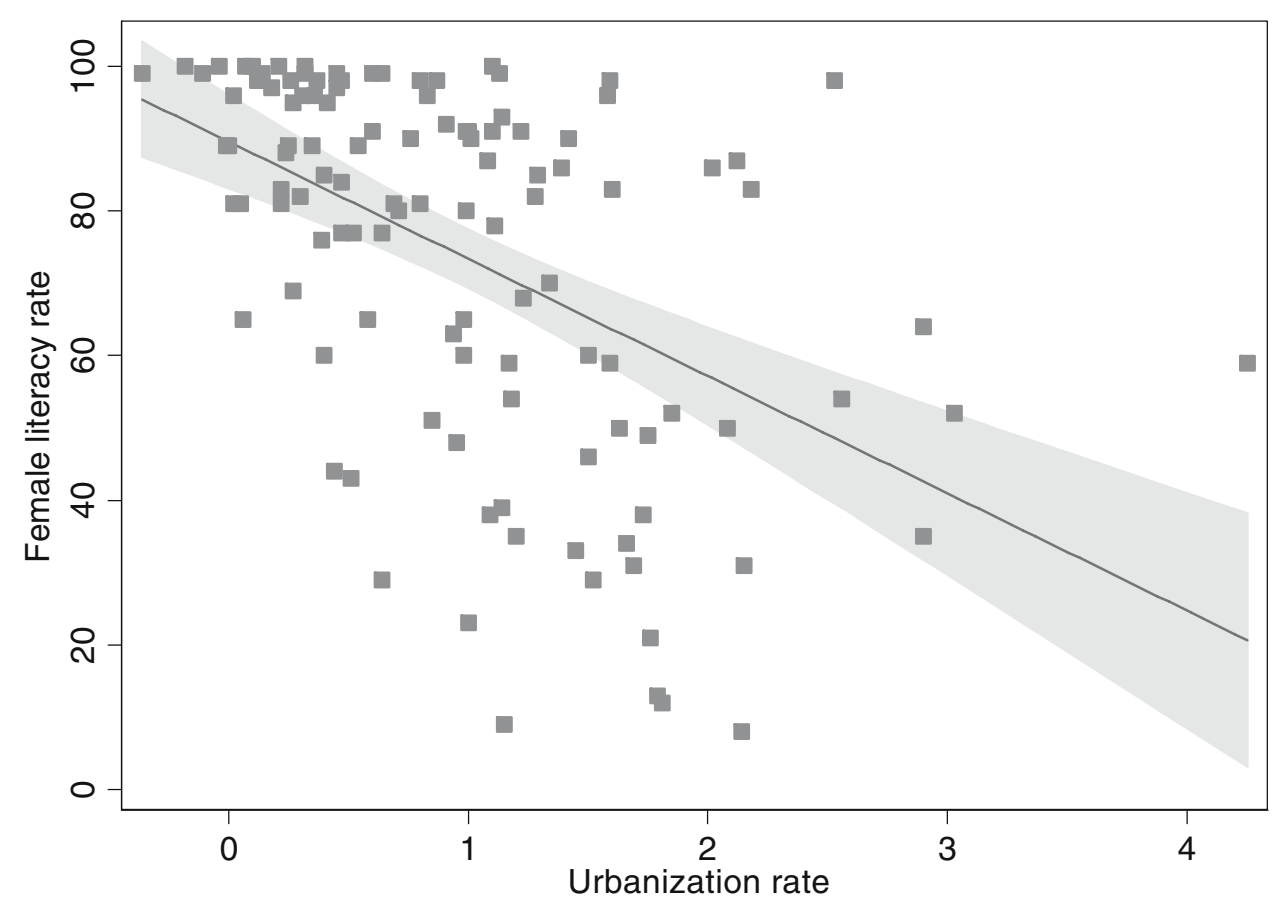

FIGURE 2. Female literacy rate and urbanization rate.

differences attributable only to the presence or absence of an etiologic agent. Among exposed groups, there is often differential risk for exposure due to one or more SDH. SDH variables are also needed to evaluate interventions. It is not enough to document if an intervention works; rather, it is important to understand how it works and who it works for. Finally when monitoring established programs, it is also necessary to monitor impacts on $\mathrm{SDH}$ and ensure that the positive effects of a program are experienced by all.

Table 2 provides examples of possible variables that can be used to measure $\mathrm{SDH}$ at the individual, local, and country level. Within countries, some of these variables are available from national census bureaus. At the country level, some of these variables are available from internet-based, public access databases provided by the United Nations and other groups for multiple years. ${ }^{36,37,39,40}$ In other cases, such data are not systematically collected.

\section{Measurement Challenges}

The measurement of SDH can be complex. We can consider variables at the individual, city, region, and country level. Generally, variables more distal than individual are based on individual measurements summarized over particular geographic areas like census tracts, postal or zip codes, cities, regions, and countries. ${ }^{35,41}$ Heterogeneity with respect to data collection systems and settingspecific realities makes cross-national, and even inter-urban, analyses challenging. Furthermore, the importance or measurement of specific variables may vary by setting or disease. For example, understanding the role of racism in health care access may be important in ethnic enclaves in Europe but not in the slums of Nairobi. Poverty may be appropriately measured by low income in one setting, but in other settings, hunger may be a better measure. 
TABLE 2 Sample variables for the measurement of social determinants of health at the individual, local, and country level

\begin{tabular}{|c|c|c|}
\hline & & Sample variables \\
\hline Indicator & Individual level & Local or country level \\
\hline $\begin{array}{l}\text { Place of } \\
\text { residence }\end{array}$ & $\begin{array}{l}\text { Geocoded location } \\
\text { of residence; neighborhood of } \\
\text { residence; urban, peri-urban, } \\
\text { slum, suburban or rural } \\
\text { dwelling; perceptions of } \\
\text { neighborhoods; home } \\
\text { ownership; citizenship or } \\
\text { immigration status }\end{array}$ & $\begin{array}{l}\text { Percent urban, peri-urban, slum, } \\
\text { suburban or rural dwellers; percent } \\
\text { home owners; percent citizens; } \\
\text { percent immigrants; percent } \\
\text { undocumented immigrants }\end{array}$ \\
\hline Gender & $\begin{array}{l}\text { Gender; sex; perceived and/or } \\
\text { experienced gender and/or } \\
\text { sex discrimination; intimate } \\
\text { partner violence }\end{array}$ & $\begin{array}{l}\text { Percent women; percent men; percent } \\
\text { transgendered or other gendered; } \\
\text { rate of femicide or homicide; rate } \\
\text { of intimate partner violence; } \\
\text { women in national government }\end{array}$ \\
\hline Race/Ethnicity & $\begin{array}{l}\text { Race, ethnicity, perceived } \\
\text { and/or experienced race } \\
\text { and/or ethnicity discrimination, } \\
\text { foreign born status }\end{array}$ & $\begin{array}{l}\text { Percent in specific race/ethnicity group, } \\
\text { percent foreign born, dissimilarity } \\
\text { index (the relative separation or } \\
\text { integration of groups), }{ }^{62} \text { isolation } \\
\text { index (probability that a member } \\
\text { of one group will meet another } \\
\text { member of the same group) }\end{array}$ \\
\hline Education & $\begin{array}{l}\text { Highest educational attainment, } \\
\text { completion of specific educational } \\
\text { milestones, literacy }\end{array}$ & $\begin{array}{l}\text { Percent completing specific } \\
\text { educational milestones, literacy rate }\end{array}$ \\
\hline $\begin{array}{l}\text { Socioeconomic } \\
\text { status }\end{array}$ & $\begin{array}{l}\text { Income, education, occupation, } \\
\text { parent's education, } \\
\text { parent's occupation }\end{array}$ & $\begin{array}{l}\text { Gross domestic product (gdp), gross } \\
\text { national product (gnp), percent } \\
\text { below the poverty level, percent } \\
\text { living on }<\$ 1 \text { usd per day, median } \\
\text { income, gini coefficient }\end{array}$ \\
\hline
\end{tabular}

Collection of data for SDH indicators can be challenging at the population level. A variety of indicators are available through national governments and multinational organizations like the United Nations. Some of the more complex SDH constructs, like discrimination, are not systematically collected on a wide scale, being more often found in the academic literature. Such constructs require the use of scales, and there is often no agreement with regard to their measurement. ${ }^{42,43}$

\section{Study Designs}

Urban vs. Rural Urban vs. rural studies typically contrast urban areas with rural areas in the same country or consider morbidity and mortality in urban vs. nonurban areas. Essentially, these studies seek to determine whether the relations between a specific health condition and SDH are different in specific urban areas as compared to specific nonurban areas. Such studies are useful in drawing attention to particular health outcomes or SDH that may be more or less prevalent in urban areas and merit further investigation to examine the specific features of the urban environment that are associated with that outcome. 
There is substantial variability within urban, suburban, and rural areas. Within a city, there can be wide variation with respect to sociodemographic characteristics of residents, the level of social support, and many other variables between neighborhoods. Using a factor analysis approach, McDade and Adair ${ }^{44}$ sought to empirically evaluate different definitions of urbanicity in Cebu City (Philippines) and concluded that urban-rural comparisons are useful for only the most general studies of urbanicity and health. As we will see when we discuss intra-urban analyses, the urban-rural comparison does not tell the complete story.

More recent work has refined distinctions such as urban core, urban adjacent, urban nonadjacent, urban slums, and rural. Even these categories become blurred when considering newer phenomenon such as "edge cities," cities at major suburban transportation intersections. ${ }^{45}$ Even with such refinements in the definition of urban, urban-rural comparisons remain limited in their ability to identify what those factors may be and the pathways through which they affect the health of urban dwellers. Features in urban and rural areas change over time and some factors may not be conserved due to population migration. It is unsurprising then that different urban-rural comparisons have provided conflicting evidence about the relative burden of disease in urban and non-urban areas. At best, these studies reveal gross estimates of the magnitude and scope of health measures in broad areas by geographical areas typically defined by size and population density.

Inter-Urban Inter-urban studies typically compare health outcomes between two or more urban areas between or within countries. Such studies can simply identify differences between cities or they can begin to examine specific features of cities that influence health. Examples of the former are numerous. For example, Vermeiren et al. ${ }^{46}$ have compared mental health outcomes among adolescents in New Haven (United States), Arkhangelsk (Russia), and Antwerp (Belgium), providing insights into cross-cultural and inter-urban similarities and differences in antisocial behavior, depression, substance use, and suicide. When using the city as the unit of analytic interest, one implicitly assumes that city-level exposures are equally important for all residents, although we know there is substantial variation within cities with respect to living conditions, access to services, municipal infrastructure, and the like.

Intra-Urban Intra-urban studies typically compare health outcomes within cities and are becoming widely used to investigate specific features of the urban environment. These studies often focus on neighborhoods, specific geographic areas within a city that are generally administrative groupings like census tracts in Canada or the USA ${ }^{47,48}$ and subareas or suburbs in South Africa. ${ }^{49}$ However, it is important to note that these areas may not represent residents' perceptions of their neighborhoods.

Let us again consider the relation between SES and child malnutrition in subSaharan Africa (Table 1). As previously noted, an urban-rural analysis found that children in poorer households were more likely to be malnourished, but the disparities were higher between socioeconomic groups in urban areas as compared to rural areas; ${ }^{32}$ yet, intra-urban analyses provide a slightly different picture. Take, for example, Mozambique which experienced both rapid urban population growth and an increase in its per capita gross domestic product. Despite the economic advances, it recorded the largest intra-urban differences in malnutrition. Relying on strictly an urban-rural perspective would have masked this finding. 


\section{Methodological Tools}

A variety of qualitative and quantitative methods have been used to examine the relations between SDH in urban settings and health outcomes. Here, we focus our attention on three useful tools: case studies, ecological analyses, and multilevel methods. These methods are by no means the only acceptable methods for examining the association between SDH and specific health outcomes in urban settings. However, these three methods are widely used. Furthermore, multilevel methods allow the consideration of multiple levels of influence on an outcome simultaneously. Moving forward, the ways variables within these multiple levels of influence are associated with specific outcomes, and each other, will help in our understanding of health in urban settings and guide development of new interventions.

Case Studies The case study is a method for learning about a complex phenomenon based upon comprehensive understanding derived from extensive description and analysis of the phenomenon and the context in which it occurs. ${ }^{50}$ Case studies can contribute to a more complete and nuanced understanding of the ways that SDH influence health outcomes or processes, such as the way historical relationships between racial or ethnic groups within an urban area affect the effectiveness of a health promotion program vis à vis access, acceptance, and uptake. They are not meant to replace scientific or technical data, but rather, are meant to complement such data with narrative, anecdotal information. ${ }^{51}$ Such approaches may combine a variety of data collection methods, or may focus on use of a single data collection method including one-on-one in-depth interviews, focus groups, and observation.

Case studies may compile a variety of information about the phenomenon of interest, using both qualitative and quantitative data sources and a variety of sampling strategies. They are characterized by in-depth analyses of social relationships or processes as they unfold within a particular setting or across several settings selected on the basis of characteristics relevant to the study question. Case studies can study phenomena or programs in several settings (e.g., several urban areas selected to vary according to criteria considered theoretically important or similar interventions implemented in different sites), comparing and contrasting between sites. Such multisite case studies can help to address some of the limitations related to generalizability that pose challenges for those interested in understanding urban settings and their influence on health.

Ecological Analyses Ecological analyses consider associations using grouped or aggregated data for both exposure and outcomes. ${ }^{13}$ For example, ecological analyses can be used to consider the association between female literacy and urbanicity or urbanization (Figures 1 and 2 above) or SES and childhood malnutrition (Table 1 above). Such simple correlations can suggest country features that co-vary with measures of country-level health for further consideration. Ecological analyses have historically been the primary method used to compare cities and countries. In urban health research, ecological studies have been used for generating hypotheses. ${ }^{52}$

Although ecological analyses are potentially useful in identifying features of the urban environment that may be associated with health, there are several inherent limitations to inferences that may be drawn from ecological analyses about how these features may impact health outcomes on the individual level. Causal inferences at the individual level cannot be drawn from ecological studies. ${ }^{53}$ Such inferences are frequently referred to as the ecological fallacy, ${ }^{53}$ and highlight the limited interpretations that should be drawn from ecological studies. Still, 
ecological analysis will continue to be an urban health research tool for hypothesis generation and will continue to suggest features of cities that may be associated with health outcomes. It is important to note that ecological studies are not limited to inter-urban comparisons but can equally generate hypotheses about features of intra-urban units (e.g., neighborhoods or residential areas) and countries which can shape population health.

Multilevel Methods Multilevel analyses integrate individual-level variables with group- and macro-level variables so that multiple levels of influence can be assessed simultaneously. ${ }^{13}$ Multilevel models have been available since the 1960 s, ${ }^{54}$ although they did not come into widespread use for more than two decades due to limitations of early models. ${ }^{55}$ Multilevel analyses allow researchers to consider how specific features of cities or of units within cities (e.g., neighborhoods) contribute to individual health independent of the contribution of other individual and contextual variables. ${ }^{55-57}$

In its simplest application to urban health, a multilevel analysis uses data from individuals in multiple cities (or neighborhoods within a city) to consider whether city living independently explains interindividual variability in health status after controlling for other relevant individual characteristics. More useful to the study of urban health, however, is the consideration of how different characteristics of urban living at multiple levels may be associated with a particular health outcome. For example, multilevel analysis can test whether racial/ethnic segregation between neighborhoods is associated with individual access to preventative health care (e.g., influenza vaccination), while controlling for social ties at the neighborhood level and for individual race/ethnicity and other key variables. With multilevel analyses, researchers can evaluate the possibility that the effect of urban living on health is different within and between cities by introducing random slopes that allow for varying strengths of the associations between urban characteristics and health.

\section{Methodological Challenges}

Although we have considered each SDH individually and at one point in time, the mechanisms through which they affect health are often linked and vary over time. $\mathrm{SDH}$ in urban settings do not exist in a vacuum. In other words, the interactions among $\mathrm{SDH}$ and the interactions between specific SDH, the physical environment, the urban resource infrastructure, and the like are important. A study of middle aged men and women in Helsinki (Finland) demonstrated that socioeconomic indicators are linked and that one socioeconomic measure may mediate the effect of another. ${ }^{58}$ Furthermore, the process of urbanization then intersects with the urban environment at any one point in time through changes in sociodemographics, land use, land availability, and population impacts on agriculture and natural resources. In addition, regional, national, and international politics, events, and governance can have substantial impact on cities and citizens. Moving forward, investigations into the nature of the interactions between macro-level SDH may offer new avenues for understanding how urban living shapes the health of populations and to suggest avenues for potential intervention.

\section{SUMMARY}

The SDH are key to understanding the way in which cities affect the health of populations. SDH are important, generally, yet, can have different effects in 
different settings from urban to rural, between countries, between cities, and within cities.

The World Health Organization (WHO) is committed to improving health through the Millennium Development Goals (MDG), the first three of which are specifically focused on reduction of inequalities vis à vis poverty, education, and gender, all of which are important SDH. ${ }^{59}$ Further, the WHO Commission on Social Determinants of Health is tasked with working to reduce inequities in health by addressing SDH within countries and among global health institutions including WHO itself. ${ }^{60,61}$ Identifying and addressing disparities in SDH will certainly move the world closer to the MDG. Indeed failure to acknowledge, and more importantly, to understand the role of SDH in health and access to health and social service will hamper any effort to improve the health of the population.

\section{REFERENCES}

1. Marmot M. Social determinants of health inequalities. Lancet. 2005;365(9464):1099-1104.

2. Kim JY, Millen JV, Gershman J, Irwin A. Dying for Growth: Global Inequality and the Health of the Poor. Monroe, ME: Common Courage Press; 2000.

3. Tarlov A. Social Determinants of Health: the Sociobiological Translation. In: Blane D, Brunner E, Wilkinson R, eds. Health and Social Organization. London: Routledge; 1996:71-93.

4. World Health Organization. Commission on Social Determinants of Health. Available at: http://www.who.int/social_determinants/en/. 2005. Geneva, World Health Organization. Accessed 1-28-2007.

5. Summary of proceedings: 5 th meeting of commissioners. 5th meeting of commissioners, Nairobi, Kenya; Geneva: World Health Organization; 2006.

6. Berkman LF, Kawachi I. Social Epidemiology. New York: Oxford University Press; 2000.

7. Kawachi I, Berkman LF. Neighborhoods and Health. New York: Oxford University Press; 2003.

8. McCarthy M. Social determinants and inequalities in urban health. Rev Environ Health 2000;15(1-2):97-108, Jan.

9. Marmot M, Wilkinson RG. Social Determinants of Health. 2 edn. New York: Oxford University Press; 2006.

10. Davis M. Planet of Slums. New York: Verso; 2006.

11. Edelman B, Mitra A. Slum dwellers access to basic amenities: the role of political contact, its determinants and adverse effects. Rev Urb Reg Dev Stud. 2006;18(1):25-40.

12. McLafferty S, Grady S. Immigration and geographic access to prenatal clinics in Brooklyn, NY: A geographic information systems analysis. Am J Public Health. 2005;95(4):638-640, Apr.

13. Last JM. A Dictionary of Epidemiology. 4 edn. New York: Oxford University Press; 2001.

14. Collins FS. What we do and don't know about 'race', 'ethnicity', genetics and health at the dawn of the genome era. Nat Genet. 2004:36(11 Suppl):S13-S15, Nov.

15. National Human Genome Research Institute, Race EaGWG. The use of racial, ethnic, and ancestral categories in human genetics research. Am J Hum Genet. 2005:77(4):519-532, Oct.

16. Williams DR. Race, socioeconomic status, and health. The added effects of racism and discrimination. Ann N Y Acad Sci. 1999:896:173-188.

17. Williams DR, Neighbors HW, Jackson JS. Racial/ethnic discrimination and health: findings from community studies. Am J Public Health. 2003:93(2):200-208, Feb.

18. Tull ES, Sheu YT, Butler C, Cornelious K. Relationships between perceived stress, coping behavior and cortisol secretion in women with high and low levels of internalized racism. J Natl Med Assoc. 2005:97(2):206-212, Feb. 
19. Harris R, Tobias M, Jeffreys M, Waldegrave K, Karlsen S, Nazroo J. Effects of selfreported racial discrimination and deprivation on Maori health and inequalities in New Zealand: cross-sectional study. Lancet. 2006:367(9527):2005-2009, Jun.

20. Harris R, Tobias M, Jeffreys M, Waldegrave K, Karlsen S, Nazroo J. Racism and health: the relationship between experience of racial discrimination and health in New Zealand. Soc Sci Med. 2006:63(6):1428-1441, Sep.

21. Karlsen S, Nazroo JY. Relation between racial discrimination, social class, and health among ethnic minority groups. Am J Public Health. 2002:92(4):624-631, Apr.

22. Schulz AJ, Gravlee CC, Williams DR, Israel BA, Mentz G, Rowe Z. Discrimination, symptoms of depression, and self-rated health among African American women in Detroit: Results from a longitudinal analysis. Am J Public Health. 2006:96(7):1265-1270, Jul.

23. Kwate NO, Valdimarsdottir HB, Guevarra JS, Bovbjerg DH. Experiences of racist events are associated with negative health consequences for African American women. J Natl Med Assoc. 2003:95(6):450-460, Jun.

24. Phillips SP. Defining and measuring gender: a social determinant of health whose time has come. Int J Equity Health. 2005:4:11, Jul.

25. Political Declaration on HIV/AIDS. A/RES/60/262, United Nations General Assembly, 2006.

26. Braveman PA, Cubbin C, Egerter S, et al. Socioeconomic status in health research: one size does not fit all. JAMA. 2005:294(22):2879-2888, Dec.

27. Burrows S, Laflamme L. Living circumstances of suicide mortality in a South African city: an ecological study of differences across race groups and sexes2. Suicide Life Threat Behav. 2005:35(5):592-603, Oct.

28. Steenland K, Halperin W, Hu S, Walker JT. Deaths due to injuries among employed adults: the effects of socioeconomic class. Epidemiology. 2003:14(1):74-79, Jan.

29. Taylor R, Page A, Morrell S, Harrison J, Carter G. Mental health and socio-economic variations in Australian suicide. Soc Sci Med. 2005:61(7):1551-1559, Oct.

30. Measuring health inequalities: gini coefficient and concentration index. Epidemiol Bull. 2001:22(1):3-4, Mar.

31. Subramanian SV, Delgado I, Jadue L, Vega J, Kawachi I. Income inequality and health: multilevel analysis of Chilean communities. J Epidemiol Community Health. 2003: 57(11):844-848, Nov.

32. Fotso JC. Child health inequities in developing countries: differences across urban and rural areas. Int J Equity Health. 2006:5:9.

33. Winkleby MA, Jatulis DE, Frank E, Fortmann SP. Socioeconomic status and health: how education, income, and occupation contribute to risk factors for cardiovascular disease. Am J Public Health. 1992:82(6):816-820, Jun.

34. Lindström M, Moghaddassi M, Merlo J. Individual and contextual determinants of selfreported poor psychological health: a population-based multilevel analysis in southern Sweden. Scand J Public Health. 2006:34(4):397-405.

35. Perova NV, Davis CE, Tao S, et al. Multi-country comparison of plasma lipid relationship to years of schooling in men and women. Int J Epidemiol. 2001:30(2): 371-379, Apr.

36. United Nations. World Urbanization Prospects: The 2005 Revision Population Database. 2006. New York, United Nations, Department of Economic and Social Affairs, Population Division.

37. United Nations Children's Fund. The State of the World's Children 2006. 2006. New York, UNICEF.

38. Montgomery MR, Stren R, Cohen B, Reed HE. Panel on Urban Population Dynamics. Cities transformed: Demographic Change and its Implications for the Developing World. Washington, DC: National Academies Press; 2003.

39. United Nations. Human development report 2003. New York: United Nations; 2003. Available at: http://hdr.undp.org/reports/global/2003/.

40. Inter-Parliamentary Union. Women in Parliament. 2006. 
41. Krieger N, Chen JT, Waterman PD, Rehkopf DH, Subramanian SV. Race/ethnicity, gender, and monitoring socioeconomic gradients in health: a comparison of area-based socioeconomic measures-the public health disparities geocoding project. Am J Public Health. 2003:93(10):1655-1671, Oct.

42. Lochner K, Kawachi I, Kennedy BP. Social capital: a guide to its measurement. Health Place. 1999:5(4):259-270, Dec.

43. Pilkington P. Social capital and health: measuring and understanding social capital at a local level could help to tackle health inequalities more effectively. J Public Health Med. 2002:24(3):156-159, Sep.

44. McDade TW, Adair LS. Defining the "urban" in urbanization and health: a factor analysis approach. Soc Sci Med. 2001:53(1):55-70, Jul.

45. Garreau J. Edge City: Life on the New Frontier. New York: Doubleday; 1991.

46. Vermeiren R, Schwab-Stone M, Deboutte D, Leckman PE, Ruchkin V. Violence exposure and substance use in adolescents: findings from three countries. Pediatrics. 2003: 111(3):535-540, Mar.

47. Glazier RH, Vahabi M, Damba C, et al. Defining needs-based urban health planning areas is feasible and desirable: a population-based approach in Toronto, Ontario. Can J Public Health. 2005:96(5):380-384, Sep.

48. Krieger N, Waterman PD, Chen JT, Soobader MJ, Subramanian SV. Monitoring socioeconomic inequalities in sexually transmitted infections, tuberculosis, and violence: geocoding and choice of area-based socioeconomic measures-the public health disparities geocoding project (US). Public Health Rep. 2003:118(3):240-260, May.

49. Niekerk AV, Reimers A, Laflamme L. Area characteristics and determinants of hospitalised childhood burn injury: a study in the city of Cape Town. Public Health. 2006:120(2):115-124, Feb.

50. United States General Accounting Office, Program Evaluation and Methodology Division. Case Study Evaluations. Washington, DC: United States General Accounting Office; 1990.

51. Banta HD, Cohen D, Eklund L, Leys M, Petticrew M, Watson S. Handbook for evidence based working and case study writing. Available at: http://www.euro.who.int/document/ ENI/Handbook_case_study.pdf. 2005. Copenhagen, World Health Organization Regional Office for Europe. Accessed 1-29-2007.

52. Galea S, Schultz A. Methodologies for the Study of Urban Health: How Do We Best Assess How Cities Affect Health? In: Freudenberg N, Galea S, Vlahov D, eds. Cities and the Health of the Public. Nashville: Vanderbilt University Press; 2005.

53. Gordis L. Epidemiology. 3 edn. Philadelphia: Saunders; 2004.

54. Elston RC, Grizzle JE. Estimation of time response curves and their confidence bands. Biometrics. 1962:18:148-159.

55. Raudenbush SW, Bryk AS. Hierarchical Linear Models. 2 edn. Thousand Oaks, CA: Sage; 2002:1.

56. Luke DA. Multilevel Modeling. Thousand Oaks, CA: Sage; 2004:1.

57. Diez Roux AV. Investigating neighborhood and area effects on health. Am J Public Health. 2001:91(11):1783-1789, Nov.

58. Lahelma E, Martikainen P, Laaksonen M, Aittomäki A. Pathways between socioeconomic determinants of health. J Epidemiol Community Health. 2004:58(4):327-332, Apr.

59. United Nations. UN Millenium Development Goals. Available at: http://www.un.org/ millenniumgoals/. 2005. Accessed 1-28-2007.

60. Lee JW. Address to the 57th World Health Assembly. Available at: http://www.who.int/ dg/lee/speeches/2004/wha57/en/index.html. World Health Organization; Geneva, May 17, 2004. Accessed January 28, 2007.

61. Lee JW. Public health is a social issue. Lancet. 2005:365(9464):1005-1006, Mar.

62. Lopez R. Segregation and black/white differences in exposure to air toxics in 1990. Environ Health Perspect. 2002:110 (Suppl 2):289-295, Apr.

63. Acevedo-Garcia D. Residential segregation and the epidemiology of infectious diseases. Soc Sci Med. 2000:51(8):1143-1161, Oct. 